\title{
Traction strategy with clips and rubber band allows complete en bloc endoscopic submucosal dissection of laterally spreading tumors invading the appendix
}

Endoscopic submucosal dissection (ESD) is now the reference method for en bloc resection of large colorectal neoplasia [1]. Nevertheless, appendix invasion is still considered a contraindication to resection because of the risk of perforation and the difficulty in finding the dissection space at the bottom of the appendix. We report on the case of a 72-yearold man referred for resection of a $4 \mathrm{~cm}$ granular laterally spreading tumor (LST) of the cecum ( $\triangleright$ Fig.1, \Video 1). The lesion had developed on the appendiceal orifice, invading it deeply.

As previously demonstrated, we used a traction strategy with two clips and a rubber band [2]. After complete circumferential incision and trimming, we caught the lesion edge with the first clip, which was grasping a rubber band ( $\vee$ Fig.2). The second clip was then used to grasp the rubber band and stretch the lesion; the clip was then fixed to the opposite wall of the colon ( $\mathbf{F i g . 3}$ ). This traction method is flexible using stretching and relaxing of the rubber band to produce more or less traction, respectively. Greater stretching of the band resulted in strong traction, which allowed the mucosa of the appendix to be dissected and extracted through the appendiceal orifice ( Fig.4). Finally, we were able to cut the deep fibrotic fibers that fixed the mucosa at the bottom of the appendix. Pathological examination revealed a granular LST with high grade dysplasia, which was completely removed with free margins.

There were no complications either during the procedure or in the postoperative period. The patient was monitored for 48 hours, given the known risk of early and late acute appendicitis of $3 \%$ and $5 \%$, respectively [3]. In patients with an intact appendix, there is a high risk of incomplete resection for lesions that reach and enter the appendiceal orifice with invisible margins (Type 3) [4].


Fig. 1 Granular laterally spreading tumor with regular mucosal and vascular patterns. a White-light imaging; the appendiceal orifice is indicated by the blue arrow. $\mathbf{b}$ Far view with narrow-band imaging (NBI). c, d Close-up views with NBI.
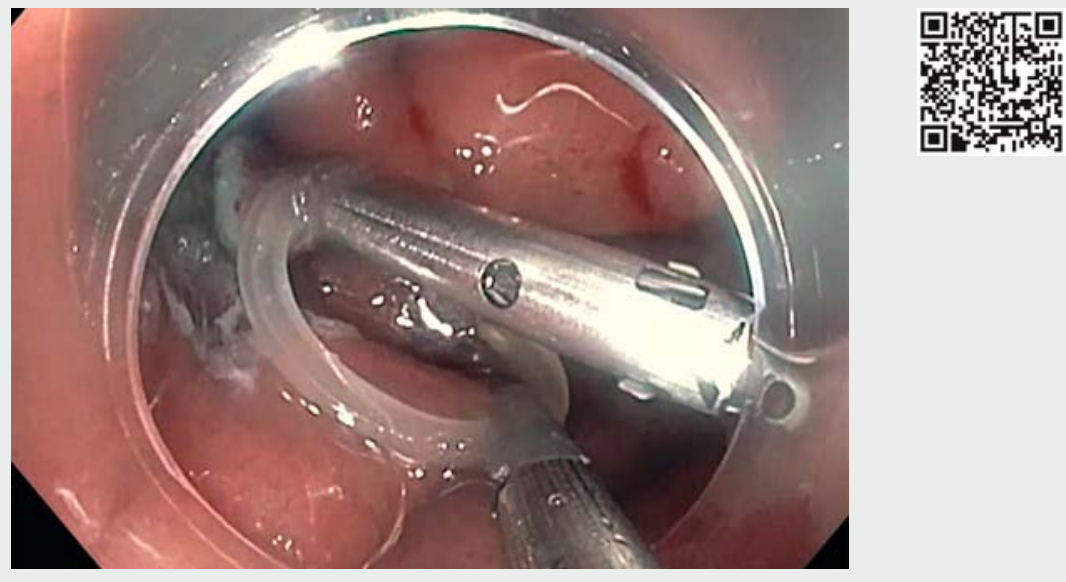

$\checkmark$ Video 1 Endoscopic submucosal dissection procedure with double clip and rubber band traction to allow complete $\mathrm{R} 0$ resection of a laterally spreading tumor invading the appendix. 


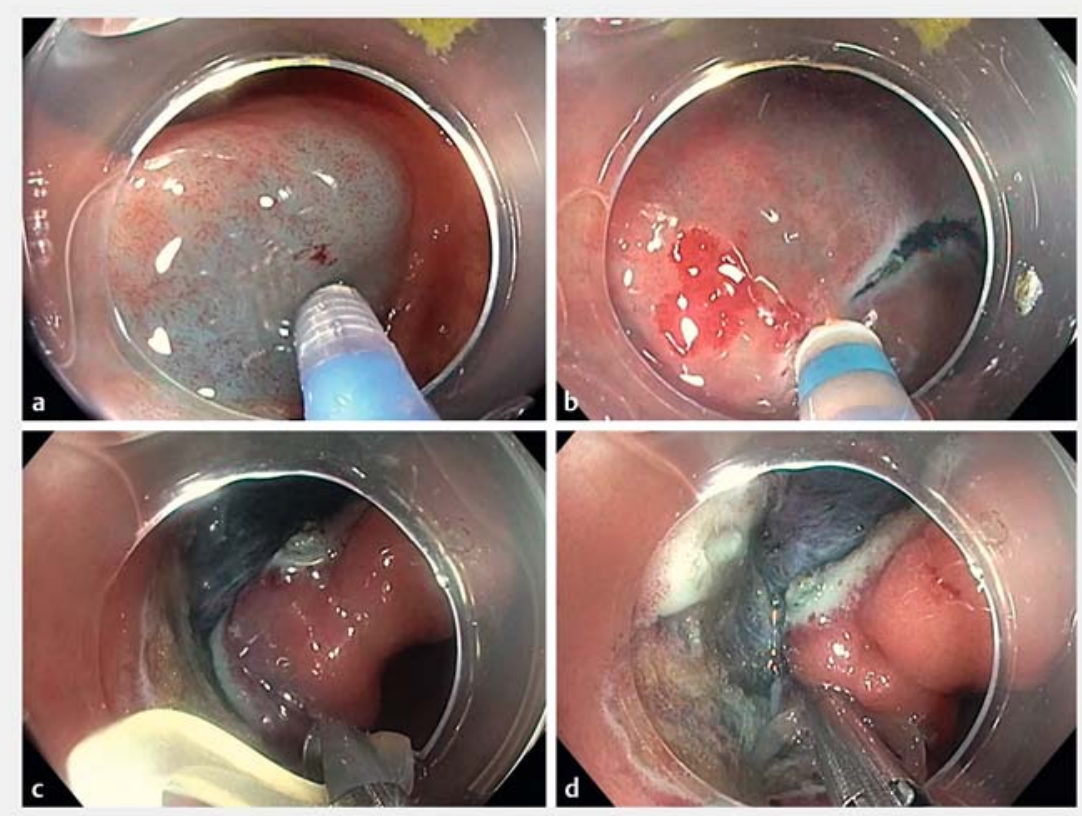

- Fig. 2 First part of the endoscopic submucosal dissection procedure. a Injection at the distal edge of the lesion. $\mathbf{b}$ Incision passing across a telangiectasia. $\mathbf{c}$ Rubber band with the first clip. d Fixation of the first clip on the lateral dissected edge of the lesion.
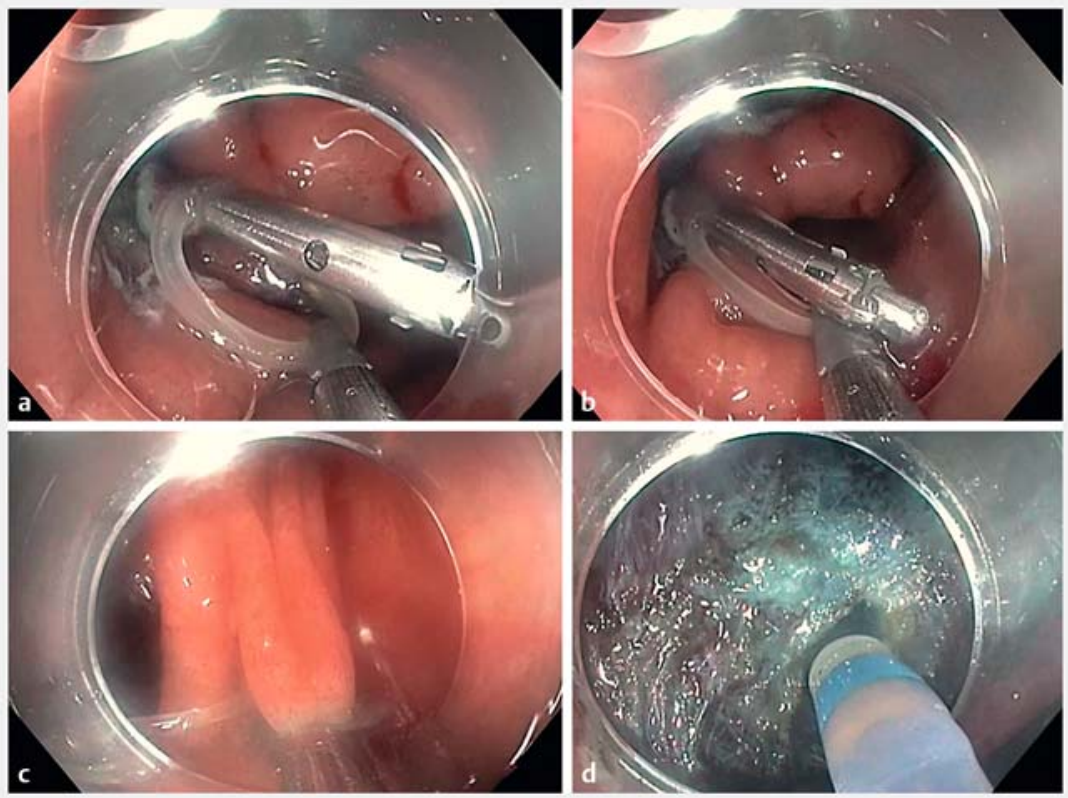

- Fig. 3 Second part of the endoscopic submucosal dissection procedure. a Rubber band grasped by the second clip. b, $\mathbf{c}$ Traction and then fixation on the opposite wall of the colon. d Easier submucosal dissection with strong traction.
Thus, appendiceal ESD is complex because of the technical difficulty in obtaining a complete resection, but the procedure seems feasible with traction methods [5].

Endoscopy_UCTN_Code_TTT_1AQ_2AD

Competing interests

None

The Authors

Erika Utzeri ${ }^{1}$, Jérémie Jacques ${ }^{2}$, Aurélie Charissoux ${ }^{3}$, Jérôme Rivory ${ }^{1}$, Romain Legros ${ }^{2}$, Thierry Ponchon ${ }^{1,4}$, Mathieu Pioche ${ }^{1,4}$

1 Department of Endoscopy and

Gastroenterology, Edouard Herriot Hospital, Lyon, France

2 Department of Endoscopy and Gastroenterology, Limoges University Hospital, Limoges, France

3 Department of Digestive Pathology, Limoges University Hospital, Limoges, France

4 Inserm U1032 LabTau, Lyon, France

\section{Corresponding author}

\section{Mathieu Pioche, MD}

Endoscopy Unit - Digestive Disease Department, Pavillon L, Edouard Herriot Hospital, 69437 Lyon Cedex, France Fax: +33-4-72110147

mathieu.pioche@chu-lyon.fr

\section{References}

[1] Saito Y, Uraoka T, Yamaguchi Y et al. A prospective, multicenter study of 1111 colorectal endoscopic submucosal dissections (with video). Gastrointest Endosc 2010; 72: $1217-1225$

[2] Jacques ], Legros R, Charissoux A et al. A combination of pocket, double-clip countertraction, and isolated HybridKnife as a quick and safe strategy for colonic endoscopic submucosal dissection. Endoscopy 2017; 49: E134-E135 

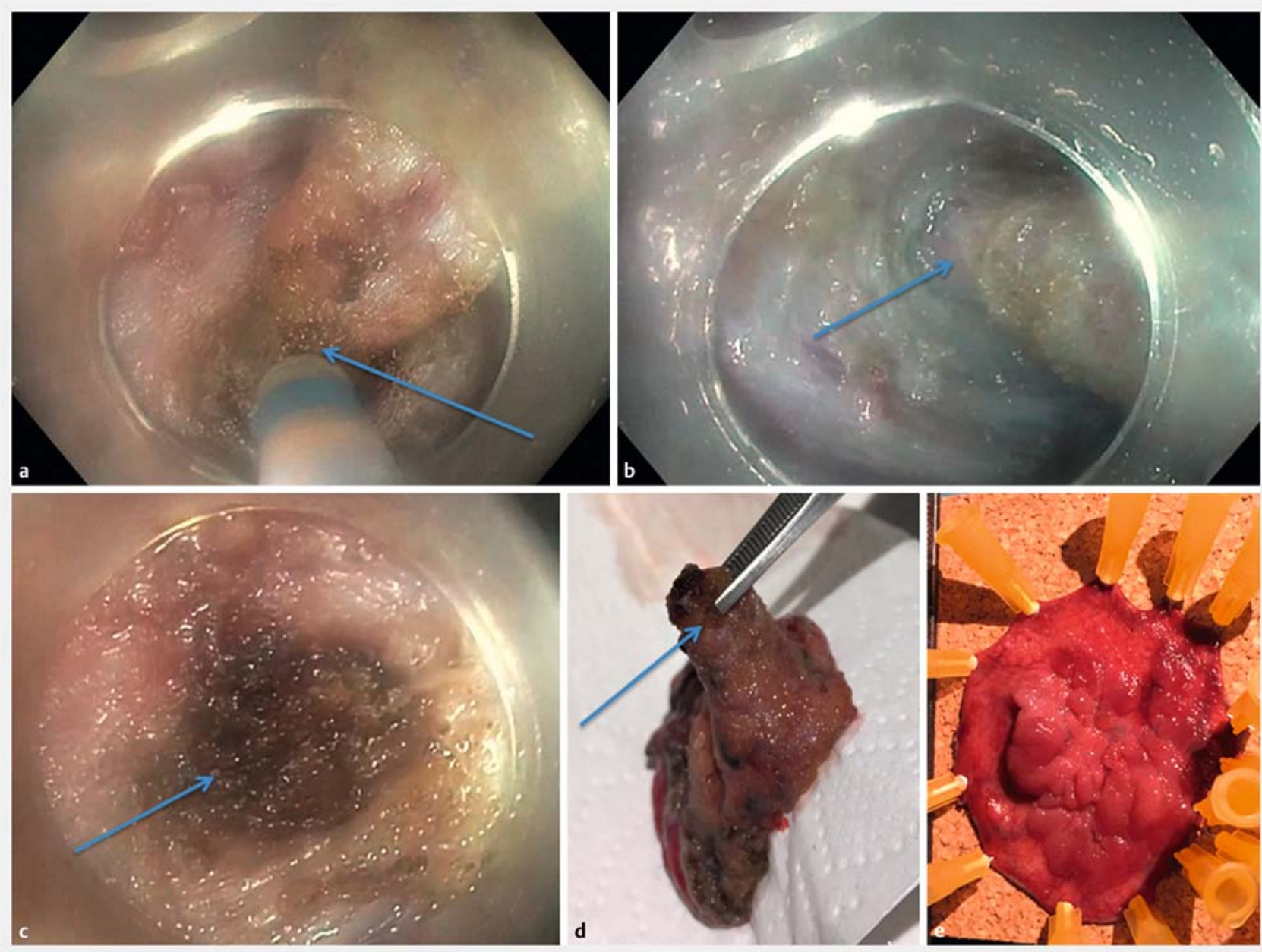

> Fig. 4 End of dissection. a Traction on the specimen stretched the appendix (arrow) away from its orifice. b Traction on the appendix (arrow). c Appendiceal resected area (arrow) with fibrosis and coagulated tissues. $\mathbf{d}$ Specimen with appendix (arrow) in the forceps. e Specimen stretched onto cork.

[3] lacopini F, Gotoda T, Montagnese F et al. Underwater endoscopic submucosal dissection of a nonpolypoid superficial tumor spreading into the appendix. VideoGIE 2017; $2: 82-84$

[4] Jacob H, Toyonaga T, Ohara Y et al. Endoscopic submucosal dissection of cecal lesions in proximity to the appendiceal orifice. Endoscopy 2016; 48: 829-836

[5] Takeda T, Murakami T, Sakamoto N et al. Traction device to remove an adenoma in the appendiceal orifice by endoscopic submucosal dissection. Endoscopy 2013; 45: E239-240

\section{Bibliography}

DOI https://doi.org/10.1055/s-0043-111713

Published online: 14.6.2017

Endoscopy 2017; 49: 820-822

(c) Georg Thieme Verlag KG

Stuttgart · New York

ISSN 0013-726X

\section{ENDOSCOPY E-VIDEOS \\ https://eref.thieme.de/e-videos}

口的回 Endoscopy E-Videos is a free access online section, reporting 尚社 on interesting cases and new techniques in gastroenterological endoscopy. All papers include a high quality video and all contributions are freely accessible online.

This section has its own submission website at

https://mc.manuscriptcentral.com/e-videos 